\title{
Optimizing the Tungsten Deposition Process
}

\author{
Rami Saad ${ }^{1}$, Michal Silberg ${ }^{1}$, Yigal Dafne ${ }^{1}$ and Zvi Lando ${ }^{2}$ \\ ${ }^{1}$ Intel Electronics, Jerusalem, Israel; ${ }^{2}$ Applied.Materials Ltd.
}

\begin{abstract}
This study was aimed at reducing the deposition temperature of the hydrogen reduction phase of blanket CVD deposition of tungsten for plug applications in the VLSI industry. Working at a lower temperature provides better step coverage, thus a thinner layer of tungsten is needed to fill the plugs. Additionally, a lower temperature process is safer for the metal lines and might increase the life time of the chamber hardware. It is known that a lower temperature would result in a lower deposition rate, but it can be compensated by a higher partial pressure of hydrogen. The results of this approach will be presented in this paper. We found that a higher flow of hydrogen, at a lower temperature, will provide us with the current deposition rate. Also presented in this paper are the effects of reducing the process temperature on some of the other film and process properties, mainly deposition rate repeatability and film stress.
\end{abstract}

\section{INTRODUCTION}

Decreasing dimensions of the structures in integrated circuits impose stringent conditions on materials and fabrication techniques. Scaling rules dictate that contact dimensions decrease with shrinking device geometries. The techniques used for contact formation in the one-micron and larger technologies will not be viable for the submicron generations. Blanket CVD tungsten deposition followed by etch back is being used as an effective contact technique in the submicron technology due to its good step coverage for high aspect ratio vias and adequate film thickness uniformity. Prior to the deposition of the tungsten layer, an adhesion layer is required due to tungsten's poor adhesion to oxides. There are several CVD reactions for tungsten deposition. The most common two are described in Equations (la, lb). The silane reduction process, Eq. (la), is driven by silane concentration while the hydrogen undergoes a reduction process, Eq. (lb) is temperature-driven and highly conformal with good step coverage. The deposition of the tungsten layer consists of two steps. The first step is a thin nucleation layer formed by silane reduction followed by a thick layer formed by the hydrogen reduction process, to achieve good step coverage. Figure 1 describes the steps required to form tungsten contacts and vias.

$$
\begin{gathered}
3 \mathrm{H}_{2}+\mathrm{WF}_{6} \rightarrow \mathrm{W}+6 \mathrm{HF} \\
3 \mathrm{SiH}_{4}+2 \mathrm{WF}_{6} \rightarrow 2 \mathrm{~W}+2 \mathrm{SiF}_{4}+6 \mathrm{H},
\end{gathered}
$$

\section{EXPERIMENTAL}

The tungsten deposition was performed in an Applied Materials Precision 5000 system. This system

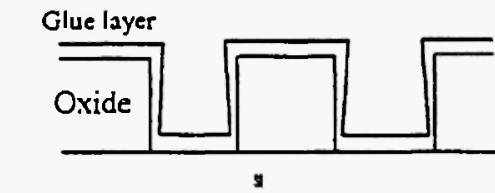

a. Contact formation and glue layer deposition

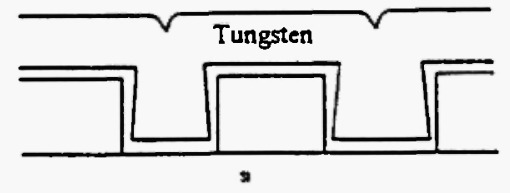

b.Tungsten deposition.

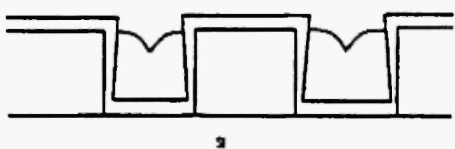

c. Tungsten and glue layers etchback.

Fig. 1: Steps required to form tungsten contacts. 
Table 1

Experimental Results

\begin{tabular}{|c|c|c|c|c|c|c|c|c|c|}
\hline $\begin{array}{l}\text { Temp. } \\
{ }^{\circ} \mathrm{C}\end{array}$ & $\begin{array}{l}\mathrm{H}_{2} \\
\text { Partial } \\
\text { Pressure/Flow } \\
\text { torr/socem }\end{array}$ & $\begin{array}{l}\mathrm{WF}_{6} \\
\text { Partial } \\
\text { Pressure/Flow } \\
\text { torr/soem }\end{array}$ & $\begin{array}{l}\text { Thick. } \\
\text { nm }\end{array}$ & $\begin{array}{l}\text { Dep } \\
\text { Rate } \\
\mathrm{nm} / \mathrm{sec}\end{array}$ & $\begin{array}{l}\text { Stress } \\
\text { Dyn/ } \mathrm{cm}^{2} \\
{\mathrm{x} 10^{9}}^{2}\end{array}$ & $\begin{array}{l}\text { Sheet } \\
\text { Resistance } \\
\mathrm{m} \Omega / \text { square }\end{array}$ & $\begin{array}{c}\text { Unif. } \\
\%\end{array}$ & $\begin{array}{l}\text { Bulk } \\
\text { Res. } \\
\mu \Omega \text {-cm. }\end{array}$ & Refl. \\
\hline 445 & $31 / 1376$ & $1.67 / 74$ & 1000 & 9.1 & 1.36 & 108 & 3.14 & 10.8 & 69.4 \\
\hline 430 & $31 / 1376$ & $1.67 / 74$ & 800 & 7.3 & 1.53 & 137 & 2.74 & 10.96 & 76.3 \\
\hline 445 & $31 / 1376$ & $1.67 / 74$ & 1000 & 9.1 & 1.36 & 105 & 2.62 & 10.5 & 68.6 \\
\hline 445 & $31 / 1376$ & $1.67 / 74$ & 1000 & 9.1 & 1.36 & 105.9 & 2.77 & 10.6 & 68.6 \\
\hline 445 & $37 / 1880$ & $1.67 / 85$ & 1040 & 9.5 & 1.35 & 94.37 & 2.96 & 9.81 & 64.4 \\
\hline 460 & $25 / 980$ & $1.47 / 58$ & 940 & 8.6 & 1.09 & 107 & 3.28 & 10.05 & 75.5 \\
\hline 445 & $31 / 1381$ & $1.86 / 83$ & 1000 & 9.1 & 1.25 & 103.7 & 2.77 & 10.37 & 64.6 \\
\hline 445 & $31 / 1376$ & $1.67 / 74$ & 1000 & 9.1 & 1.21 & 106.2 & 2.69 & 10.62 & 68.6 \\
\hline 460 & $31 / 1376$ & $1.67 / 74$ & 1180 & 10.7 & 1.04 & 85.49 & 2.86 & 10.09 & 65.5 \\
\hline 430 & $37 / 1888$ & $1.86 / 95$ & 940 & 8.5 & 1.4 & 123.7 & 2.97 & 11.63 & 73.0 \\
\hline 445 & $31 / 1376$ & $1.67 / 74$ & 1000 & 9.1 & 1.28 & 106.6 & 2.64 & 10.66 & 68.8 \\
\hline 460 & $37 / 1871$ & $1.47 / 74$ & 1200 & 10.9 & 1.18 & 80.4 & 2.6 & 9.65 & 71.7 \\
\hline 460 & $37 / 1888$ & $1.86 / 95$ & 1280 & 11.6 & & 73.1 & 2.5 & 9.35 & 55.4 \\
\hline 430 & $25 / 988$ & $1.86 / 73$ & 760 & 6.9 & 1.49 & 159 & 1.85 & 12.08 & 78.6 \\
\hline 445 & $31 / 1376$ & $1.67 / 74$ & 1000 & 9.1 & 1.21 & 106.2 & 2.82 & 10.62 & 68.6 \\
\hline 445 & $31 / 1370$ & $1.47 / 65$ & 920 & 8.4 & 1.21 & 110.3 & 2.71 & 10.15 & 73.5 \\
\hline 430 & $37 / 1871$ & $1.47 / 74$ & 860 & 7.8 & 1.54 & 127 & 2.99 & 10.92 & 77.8 \\
\hline 445 & $25 / 984$ & $1.67 / 66$ & 920 & 8.4 & 1.16 & 123 & 2.37 & 11.3 & 71.6 \\
\hline 430 & $25 / 980$ & $1.47 / 58$ & 820 & 7.5 & 1.28 & 164 & 1.57 & 13.45 & 82.8 \\
\hline 460 & $25 / 980$ & $1.86 / 73$ & 1040 & 9.5 & 1.17 & 94.5 & 3.99 & 9.83 & 60.4 \\
\hline
\end{tabular}

Table 2

Summary of parameter influence on process properties

\begin{tabular}{|l|l|l|l|l|l|l|}
\hline & $\begin{array}{l}\text { Dep Rate } \\
\mathrm{nm} / \mathrm{sec}\end{array}$ & $\begin{array}{l}\text { Stress } \\
\text { dyen/cm² E9 }\end{array}$ & $\begin{array}{l}\text { Bulk Resistivity } \\
\mu-\mathrm{cm}\end{array}$ & $\begin{array}{l}\text { Uniformity } \\
\%\end{array}$ & $\begin{array}{l}\text { Reflectivity } \\
\%\end{array}$ & $\begin{array}{l}\text { Sheet } \\
\text { Res. } \\
\mathrm{m} \Omega / \mathrm{sq} .\end{array}$ \\
\hline $\begin{array}{l}\text { Temperature } \\
430 \rightarrow 460^{\circ} \mathrm{C}\end{array}$ & +2.6 & -0.35 & -2 & +0.7 & -12 & -54 \\
\hline $\begin{array}{l}\mathrm{H}_{2} \text { P.Pressure } \\
25 \rightarrow 37 \text { torr }\end{array}$ & +1.5 & +0.12 & -1 & +0.1 & -5.5 & -30 \\
\hline $\begin{array}{l}\text { WF } \mathrm{F}_{6} \text { P.Pressure } \\
1.47 \rightarrow 1.86 \text { torr }\end{array}$ & +0.5 & +0.02 & -0.2 & +0.3 & -10 & -7 \\
\hline
\end{tabular}

is a single-wafer cold wall reactor. The wafers are loaded onto a susceptor which is heated from below by an array of $1000 \mathrm{~W}$ lamps. The reactant and carrier gases are introduced from above the wafers through a showerhead. The thickness was determined by SEM cross section. Sheet resistance and its uniformity were measured by a four-point probe, Prometrix system, using an edge exclusion of $6 \mathrm{~mm}$. Resistivity was calculated as the product of tungsten thickness and the average sample sheet resistance. Reflectivity was measured versus $\mathrm{Si}<100\rangle$ at $480 \mathrm{~nm}$ using the Prometrix FT750 system. SEM was used also for step 
coverage measurement. Stress was determined by the wafer curvature method using the FSM 8800. Three independent experiments were done in order to determine the influence of the temperature, $\mathrm{H} 2$ partial pressure and $\mathrm{WF}_{6}$ partial pressure on the following parameters: dep. rate, resistivity, wafer uniformity, stress, grain roughness and step coverage. This paper will present all the results but will only discuss the effects on dep. rate, stress and step coverage.

Experiment 1:

This experiment was carried out on 6" blank $\mathrm{Si}$ $<100>$ wafers with $50 \mathrm{~nm}$ of TiN deposited on them. The purpose of this experiment was to explore the influence of the input parameters on the output parameters.

A CCF 6 center points - a quadratic module design of experiment - was carried out. The parameter settings for the matrix were based on a previous work $/ 1,2 /$.

The inlet parameters were changed as follows:

Temperature : $\quad 430-445-460^{\circ} \mathrm{C}$.

H2 p.p : $\quad$ 25-31-37 torr. $(\sim 1000-1900 \mathrm{sccm})$

$\mathrm{WF}_{6}$ p.p. : $\quad 1.47-1.67-1.86$ torr $(-60-90 \mathrm{sccm})$.

\section{Experiment 2}

Based on the results of experiment \#1, a tungsten layer was deposited on patterned wafers. These wafers consisted of a BPSG layer with contact holes with an aspect ratio of 2; on the BPSG layer a TiN adhesion layer was deposited. Four different configuration set ups were used to give a required tungsten layer thickness of $420 \mathrm{~nm}$. The use of a thinner layer than is needed to completely fill the contact was necessary in order to be able to measure the step coverage.

\section{Experiment 3}

Based on the results of experiment \#2, a third experiment was carried out in order to understand the change in deposition rate that was found between patterned and unpatterned wafers. Tungsten was deposited on patterned wafers (BoronPhosphorusSiliconGlass with contact holes, and a $\mathrm{TiN}$ adhesion layer) for only $60 \mathrm{sec}$, with $\mathrm{WF}_{6}$ flow of $50,60,90 \mathrm{sccm}$. It is known that the hydrogen reduction of $\mathrm{WF}_{6}$ has two kinetic regimes, one mass transfer limited and the other surface-controlled. In order to identify the region of transfer between the different kinetic regimes, 6 wafers were processed at $475^{\circ} \mathrm{C}$, hydrogen flow of $800 \mathrm{sccm}$ and at different flows of $\mathrm{WF}_{6}$ for $110 \mathrm{sec}$ deposition time. For each wafer we measured the sheet resistance and the stress.

\section{RESULTS}

\section{Deposition Rate}

From the results it can be noted that:

1. The deposition rate depends strongly on the temperature and the partial pressure of hydrogen.

2. The decrease in deposition rate, which will result from a lower temperature process, can be compensated by a higher hydrogen partial pressure.

The Analysis of Variance (Anova) calculated from the design of the experiment shows that there is an interaction effect between the gases and the temperature with regard to deposition rate.

From Table 3, which summarizes the step coverage experiment data, it can be seen that the deposition rate on the patterned test wafers was lower, approximately by $15 \%$, than that on unpatterned wafers.

This intriguing result was received from tests \#2, 3, 4 , while the deposition rate of test \#1 was not changed. Table 4, which summarizes the influence of the pattern on the deposition rate, shows that the change in deposition rate between patterned and unpatterned wafers depends on $\mathrm{WF}_{6}$ flow.

By plotting the change in thickness represented by the sheet resistance versus the $\mathrm{WF}_{6}$ flow, it can be seen that the thickness, i.e., dep. rate, does not change with $\mathrm{WF}_{6}$ flow from around $90 \mathrm{sccm}$ and so on. Thus the ratio 800: $50\left(\mathrm{H}_{2}: \mathrm{WF}_{6}\right)$ corresponds to a mass-transport limited reaction, and the ratio $800: 90$ to a surfacelimited reaction.

\section{Stress}

The results show that the main factor which affects the stress is the temperature. The lower the 
Table 3

Step coverage experiment results

\begin{tabular}{|c|c|c|c|c|c|c|c|c|}
\hline \multirow[b]{3}{*}{ Sample } & \multirow[b]{3}{*}{$\begin{array}{l}\text { Temperature } \\
{ }^{\circ} \mathrm{C}\end{array}$} & \multirow[b]{3}{*}{$\mathrm{WF}_{6} \mathrm{sccm}$} & \multirow[b]{3}{*}{$\begin{array}{l}\text { Dep. time } \\
\text { sec }\end{array}$} & \multirow[b]{3}{*}{$\begin{array}{l}\text { Thickness } \\
\text { nm }\end{array}$} & \multicolumn{4}{|c|}{ Step Coverage \% } \\
\hline & & & & & \multicolumn{2}{|c|}{ Center } & \multicolumn{2}{|c|}{ Edge } \\
\hline & & & & & Plug & G.ring & Plug & G.ring \\
\hline 1 & 475 & 500 & 55 & $375-420$ & 88 & 100 & 81 & - \\
\hline 2 & 475 & 500 & 55 & $380-400$ & - & 88 & - & 94 \\
\hline 3 & 475 & 500 & 55 & 400 & - & 88 & - & 94 \\
\hline 4 & 460 & 1376 & 39 & $330-360$ & - & 100 & - & 93 \\
\hline 5 & 445 & 1376 & 46 & $330-330$ & 100 & 87 & - & 100 \\
\hline 6 & 445 & 1376 & 44 & $330-360$ & 93 & 100 & - & - \\
\hline
\end{tabular}

Table 4

Summary of the influence of pattern on deposition rate

\begin{tabular}{|l|l|l|l|l|l|l|c|}
\hline Sample & $\begin{array}{l}\text { WF } \\
\text { sccm }\end{array}$ & \multicolumn{2}{l|}{$\begin{array}{l}\text { Thickness } \\
\text { nm }\end{array}$} & \multicolumn{2}{l|}{$\begin{array}{l}\text { Dep. rate } \\
\text { nm/sec }\end{array}$} & \multicolumn{2}{l|}{$\begin{array}{l}\text { Step Coverage } \\
\%\end{array}$} \\
\hline & & Patterned & Unpatterned & Patterned & Unpatterned & Patterned & Unpatterned \\
\hline 1 & 50 & $425-475$ & $520-550$ & $7-7.9$ & $8.6-9.1$ & $90-100$ & - \\
\hline 2 & 60 & - & 525 & - & 8.7 & - & 95 \\
\hline 3 & 90 & $575-600$ & 600 & $9.6-10$ & 10 & $\sim 90$ & - \\
\hline
\end{tabular}

temperature, the higher the stress. The changes in the gas flows do not affect the stress.

\section{Step Coverage}

Fig. 2a,b shows SEM pictures of a plug and a guard ring structure, partially filled with tungsten. The step coverage was measured by SEM cross section. We encountered some problems when analyzing the pictures, as will be further explained in the next section. Table 3 summarizes the step coverage experiment results.

\section{DISCUSSION AND CONCLUSIONS}

\section{Deposition Rate}

The CVD process of hydrogen reduction is a temperature-driven process, while the kinetic of this process can be determined by equation 2 17\%. This reaction is dominated by the actual reaction of the gases at the wafer surface. The temperature of the wafer is critical for this reaction. A higher flow of hydrogen will result in a higher deposition rate as long as there is "enough" $\mathrm{WF}_{6}$ around the active area. As the ratio between hydrogen and $\mathrm{WF}_{6}$ increases, the situation is changed, and a starvation for $\mathrm{WF}_{6}$ occurs. This results in a lower deposition rate which depends on the topography of the wafer. This means that in the transient regime between both regimes and in the mass transfer regime deposition, the rate on flat test wafers will be different from the rate on patterned production wafers. Moreover, it will be changed for different products, which cannot be tolerated in the fabrication.

$$
\text { dep. rate }=\mathrm{e}^{(\mathrm{Ea} / \mathrm{RT})} \cdot\left[\mathrm{P}_{\mathrm{H} 2}\right]^{0.5}
$$

\section{Stress}

A lower deposition temperature and thinner films (3) have higher stress. The assumption that stress is not a major concern since almost all of the tungsten film is removed during the etch back stage was found to be 


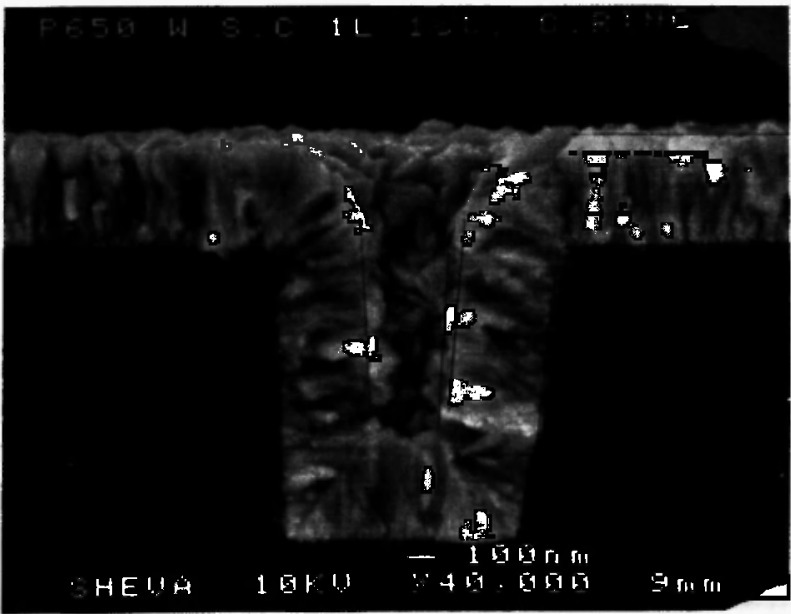

a. Step coverage in a plug

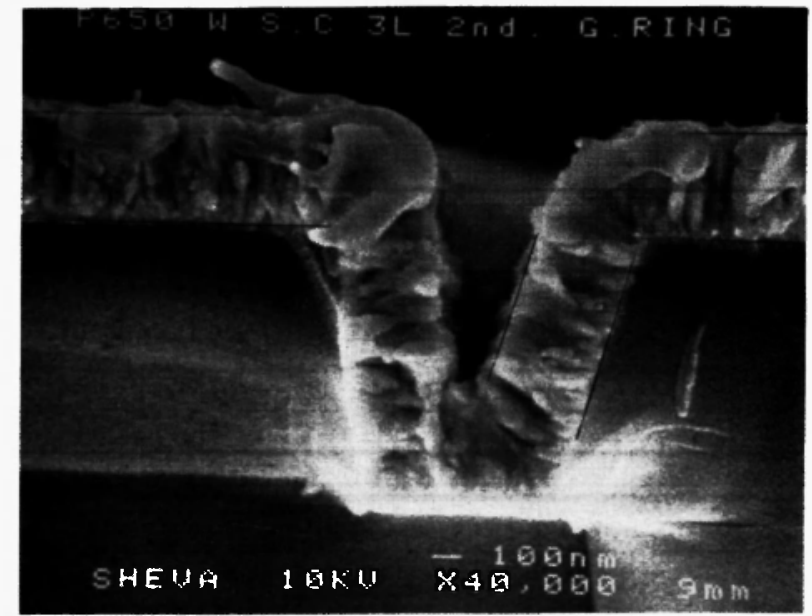

b. Step coverage in a guard ring.

Fig. 2:

wrong. It is now understood that the stress of the tungsten film might cause via delamination (open between the tungsten plug and the underlying layer), therefore it is not recommended to reduce the deposition temperature.

\section{Step Coverage}

Two main issues were raised while trying to measure the step coverage. The first problem is to find a contact cut exactly in the middle. Therefore, it was decided to base the first analysis on the measurements in the Guard-ring, in order to compare qualitatively the different configurations. The second problem, which is more general to SEM pictures, is the actual measurement of the thickness. We measure the thickness with a regular ruler, thus limiting the resolution to $1 \mathrm{~mm}$. It is also very hard to decide what is the "true" thickness, since the roughness of the film is in the order of 1-2 $\mathrm{mm}$. This problem is extremely important when one tries to determine the step coverage, which is the ratio between 2 thicknesses. The measurement error is of the order of $10 \%$. Since we are interested in a $10-15 \%$ change in step coverage, we will have to find another way to measure it. Nevertheless, it can be seen from this work and other works $/ 4,5$ / that the step coverage improves with reduction of the deposition temperature. The growth rate into the contact is limited by the con- duction of the gaseous species into the contact which can be expressed by equation $3 / 7 /$.

$$
\begin{aligned}
& Q=3.81 \cdot P / L \cdot(T . M)^{0.5} \cdot D^{3} \\
& Q-\text { Gas flow into the contact (liter/sec) } \\
& P-\text { Partial pressure } \\
& L-\text { Length of the contact } \\
& T-\text { Temperature } \\
& M-\text { Molecular weight } \\
& D-\text { Diameter of the contact. }
\end{aligned}
$$

The gas throughput to the contact is proportional to the square root of the temperature while the deposition rate is proportional to the exponent of the deposition temperature. This means that increasing the temperature will affect the deposition rate more than the throughput of the gas to the contact. Thus at high temperature the tungsten tends to deposit first at the top of the contact.

Although better step coverage can be achieved by reducing the deposition temperature, it is not wise to reduce the deposition temperature since the gain as regards improvement in the step coverage is very small while the layer stress increases significantly. Another manufacturing aspect to be considered is the decrease in the machine throughput. 


\section{REFERENCES}

1. T.K. Ramchandar, Intel internal publication, 1991.

2. Y. Dafne, Intel internal publication, 1992.

3. G.J. Leusink, T.G.M. Oosterlaken, G.C.A.M. Janssen and S. Radelaar, J. Appl. Phys., 74, 3899 (1993).

4. T.E. Clark, M. Chang and C. Leung, J. Vac. Sci. Technology B, 9, 1479 (1991).
5. T.E. Clark, M. Chang and C. Leung, Microelectronic Manufacturing and Testing, May, 35 (1990).

6. J.C. Chang, Thin Solid Films, 208, 177 (1992).

7. G. Marcyk, S. Ahmed, B. Jan, X.C. Mu, J. Multani, E. Patterson, R. Shukla and S. Sivaram, IPTC Conference, October, 1988. 